Relations industrielles

Industrial Relations

\title{
White Collar Unions in Australia, R.M. Martin, Monograph no 5, The Australian Institute of Political Science, Sydney, 1965, 40 pages.
}

\section{Ronald Pleau}

Volume 21, numéro 2, 1966

URI : https://id.erudit.org/iderudit/027683ar

DOI : https://doi.org/10.7202/027683ar

Aller au sommaire du numéro

Éditeur(s)

Département des relations industrielles de l'Université Laval

ISSN

0034-379X (imprimé)

1703-8138 (numérique)

Découvrir la revue

Citer ce compte rendu

Pleau, R. (1966). Compte rendu de [White Collar Unions in Australia, R.M.

Martin, Monograph no 5, The Australian Institute of Political Science, Sydney, 1965, 40 pages.] Relations industrielles / Industrial Relations, 21(2), 301-301.

https://doi.org/10.7202/027683ar

Tous droits réservés (C Département des relations industrielles de l'Université Laval, 1966
Ce document est protégé par la loi sur le droit d'auteur. L'utilisation des services d’Érudit (y compris la reproduction) est assujettie à sa politique d'utilisation que vous pouvez consulter en ligne.

https://apropos.erudit.org/fr/usagers/politique-dutilisation/ 
travailleur soit persuadé qu'en travaillant dans une industrie, il travaille au sein d'une collectivité et que, de son côté, la population l'accueillant soit convaincue que le migrant contribue d'une façon importante ou progrès et au bien-être de l'ensemble de la communauté.

Enfin, l'auteur formule des recommandations spécifiques concernant les méthodes d'adaptation et il nous invite, en les liasnt, à avoir présent à l'esprit le caractère de réciprocité du phénomène. Cette étude intéresse houtement tous ceux préoccupés par une utilisation rationnelle du potentiel humain de leur société.

\section{Jean-Paul Rheault}

White Collar Unions in Australia, R.M Martin, Monograph No 5. The Australian Institute of Political Science, Sydney, 1965, 40 pages

Cette récente publication fournira à qui aura l'heureuse idée de la consulter une information concise et assez complète sur la situation du syndicalisme des collets blancs en Australie.

Sans faire de distinctions entre les employés de bureau, les employés de services, les fonctionnaires, les cadres ou les professionnels, l'auteur se contente de décrire l'état actuel du syndicalisme pour le personnel occupant des fonctions non-manuelles.

C'est d'abord l'évolution rapide de ce genre de syndicalisme qui attire l'attention. Depuis 1880, I'année qui en marque les débuts, nous pouvons constater qu'il ne connaît que du succès dans presque tous les secteurs d'activités.

Puis après une énumération chronologique complète des différents genres d'associations qui se sont formées jusqu'à nos jours, l'auteur considère quelques données statistiques pour analyser l'évolution des ropports entre par exemple la main-d'oeuvre syndiquée en général et celle des travailleurs non manuels, et d'autres encore.

Nous passons ensuite à une étude de la répartition du « membership » des 347 syndicats actuels de l'Australie, dont 192 pour les collets blancs, sons oublier celle des divers types d'organisation que nous $y$ rencontrons (structures verticales et horizontoles) avec leurs principales caractéristiques.

Une troisième section est consacrée à l'analyse du changement qui se produit dans le caractère du syndicalisme des collets blancs.

11 est intéressant d'y remarquer la comparaison des caractères que l'auteur fait à cette occasion entre le syndicalisme des travailleurs non-manuels (attitudes du membership, identification de classe, comportement des syndicats).

Enfin c'est un bref exposé sur le militantisme chez ces syndicats lequel est d'une nature particulière chez les professionnels qui vient terminer les propos de R.M. Martin.

\section{Ronald Pleau}

\section{Le secret en matière d'inventions, André} Bertin, Editions du Tambourinaire. Entreprise Moderne d'Edition, Paris, 1965. 157 pages.

«Elément essentiel de force, de prestige, parfois même de survie des entreprises, "la recherche' entraîne des dépenses si considérables et oblige les chercheurs à de si grands efforts; que rien ne doit être négligé pour en sauvegarder les résultats, lorsqu'ils interviennent »... (préface)

L'auteur, dans ce volume, tente de cerner les différentes facettes du problème.

De sorte que I'on retrouve ou sommaire.

I - La nature des secrets en cause

2-Brevet ou secret: vaut-il mieux prenprendre un brevet ou garder le secret.

3-La protection du secret technique (know-how)

4- Le secret de fabrique

5-Questions connexes: limites légales au secret, le secret au cours de la génération de l'invention, les emprises générales exercées sur les secrets techniques

6-Comment intéresser les ingénieurs aux questions de propriété industrielle.

L'analyse qui est aussi faite du système octuel de brevets et de protection pour l'invention permet de constater l'inefficacité de la loi actuelle en France. L'auteur suggère alors un plan qui servirait à l'Europe pour les brevets et les secrets techniques. Certes le problème du secret technique est complexe mais, selon l'auteur, il est nécessaire d'avoir un véritable système de protection pour ne pas compromettre «profondément la génération et l'exploitation des inventions " (p. 147). 